\title{
Cruciferous vegetables consumption and the risk of ovarian cancer: a meta-analysis of observational studies
}

\author{
Bo Han ${ }^{*}$, Xuepeng Li and Tao Yu
}

\begin{abstract}
Background: To quantify the effect of cruciferous vegetable consumption on the incidence of ovarian cancer by meta-analyzing the existing observational studies and provides quantitative and high-level evidence.

Methods: A detailed literature search of Medline and EMBASE for all relevant papers published. A meta-analysis was conducted for the association between cruciferous vegetable consumption and risk of ovarian cancer.

Results: A total of 4,306 cases in 375,562 controls in 11 independent studies were identified in this current meta-analysis. The result of this current meta-analysis, including 6 case-control and 5 cohort studies, indicated that cruciferous vegetable intake was associated with a reduced risk of ovarian cancer. Cruciferous vegetable consumption was associated with a reduced risk of ovarian cancer in case-control studies ( $R R=0.84 ; 95 \% \mathrm{Cl}, 0.75-0.94)$ but not in cohort studies ( $\mathrm{RR}=1.00 ; 95 \% \mathrm{Cl}, 0.85-1.11)$.

Conclusions: The results from this meta-analysis of observational studies demonstrate that cruciferous vegetable consumption is a prospective factor of the ovarian cancer. However, more in-depth studies are warranted to report more detailed results, including other specific vegetables within the cruciferous vegetable family.
\end{abstract}

Virtual slides: The virtual slide (s) for this article can be found here: http://www.diagnosticpathology.diagnomx.eu/vs/ 1116708293115581.

Keywords: Cruciferous vegetables, Ovarian cancer, Dietary, Risk factor, Meta-analysis

\section{Introduction}

It was reported that ovarian cancer is the eighth most common cancer and the fifth most common cause of cancer death in women in the developed countries [1]. Usually it is diagnosed at an advanced stage and, therefore, despite improvements in treatment, the survival rate remains low at less than $45 \%$ after 5 years [1-4]. Marked geographic variation in incidence rates suggests an important role of behavioral and potentially modifiable factors such as diet in ovarian cancer development. However, there is no clear etiologic role of dietary intake in ovarian cancer [5]. Some epidemiological studies have shown that high consumption of vegetables reduces the risk of ovarian cancer; however, daily intake of red meat was significantly associated with the risk of ovarian cancer [6,7]. It is

\footnotetext{
*Correspondence: dochanbo@163.com

* Correspondence: dochanbo@163.com Zaozhuang, Shandong, PR China
}

important to detect the harmful or protective factors for the ovarian cancer. The realization of the relationship between the modifiable epidemiological factors and risk of ovarian cancer would provide a more effective strategy for the cancer prevention in the future.

Cruciferous vegetables are a special group of vegetables named for their cross-shaped flower petals, including cabbage, broccoli, brussels sprouts, cauliflower and other members of the family. There is accumulating evidence that cruciferous vegetable consumption may lower the risk for several types of cancers [8]. Although several epidemiological studies have focused on the association between cruciferous vegetable intake and ovarian cancer risk, their conclusions have been inconsistent. Meta-analysis is a useful statistical tool to pool the relevant studies together and gain a more powerful conclusion $[9,10]$. The meta-analysis was also used in the search for potential causes of ovarian cancer. We therefore conducted a meta-analysis of all 
published studies to gain a better understanding of the relationship between cruciferous vegetables and ovarian cancer risk.

\section{Methods}

\section{Search strategy and inclusion criteria}

We followed the Meta-Analysis of Observational Studies in Epidemiology (MOOSE) [11] and Preferred reporting items for systematic reviews and meta-analyses (PRISMA) [12] guidelines in conducting this meta-analysis. A systematic literature search was conducted through two electronic databases (Medline and EMBASE) until Dec. 5, 2013. The key words "cruciferous vegetable*" or "brassica", "diet" and "ovarian cancer" were searched as text word and exploded as medical subject headings (MeSH) where possible. The reference lists of relevant articles were reviewed for the additional studies. No language or other restrictions were set in the literature search or the inclusion criteria. If additional data was required, the corresponding authors will be contacted.

The studies were be considered included if they met the following inclusion criteria: 1) studies reported the association between cruciferous vegetable intake and risk of ovarian cancer; 2) studies obtained a case-control or cohort study design; 3) the value of relative risk (RR), odds ratio (OR) with $95 \%$ confidence intervals (CI) or the raw data to calculate them were reported.

\section{Data extraction and assessment of study quality}

The data extraction was conducted via a standardized data extraction form, collecting information on the name of first author, the publication year, study design, number of cases and controls, sample size, study site, adjustments of the confounding factors, and the OR/RR value with $95 \% \mathrm{CI}$. When the OR or RR was not reported in the article, the RR with $95 \%$ CI with the raw data and no confounding factors were adjusted.

The study quality was assessed by two reviewers back to back and any discrepancies were re solved by reevaluating the included articles and discussion with a third investigator. We obtained the Newcastle-Ottawa Scale (NOS) Assessment of the quality of the included studies [13]. The study quality was assigned to each study based on the 3 parts: selection, comparability, and exposure and outcome condition. The NOS assessed the selection, comparability and exposure of a case-control study, while the selection, comparability and outcome of a cohort study. The study with more than 6 stars would be regarded in relative high quality.

\section{Data integration and statistical methods}

The RR was obtained to approximate RR in this metaanalysis because of the low incidence rate of ovarian cancer. When both the crude and the adjusted OR/RR values were offered, only the adjusted value would be adopted for the meta-analysis. If only the raw data was reported, we would calculate the unadjusted RR.

The heterogeneity among the included studies was measured by the $X^{2}$ test and quantified with the $\mathrm{I}^{2}$ statistic. When $P$ for the heterogeneity was $<0.1$ and $I^{2}>50 \%$, the interstudy heterogeneity would be considered statistically significant. The ORs and 95\% CIs of all the included studies were pooled using the general variance-based method with a fixed-effects model unless the heterogeneity is significant. The source of the statistically significant heterogeneity was assessed by both removing the included studies one by one to measure whether any single study was the source of the heterogeneity. Another independent method to detect the source of heterogeneity was to conduct a subgroup meta-analysis. Subgroup analyses were conducted by the study designs (case-control or cohort study) and population of or hospital based design.

A sensitivity analysis was performed by excluding the included studies from the meta-analysis. The publication bias was evaluated using funnel plots and the Egger test $[14,15] . \mathrm{P}<0.1$ was considered to indicate statistically significant publication bias. All analyses were conducted using STATA software, version 12.0 (StataCorp LP, College Station, Texas).

\section{Results}

\section{Identification and selection of studies}

The flowchart of the study selection was presented in Figure 1. A total of 1392 publications were retrieved from the initial literature search (524 form the Medline, 735 from the EMBASE, and 133 from the reference lists of the relevant studies). After excluding 1237 articles with unrelated topics, a total of 155 records were detailed evaluated. Among the 155 articles, 29 full-texts were assessed for eligibility after removing 126 articles (reviews, case reports and overlapped articles). From these, 11 original articles that included data on the association between cruciferous vegetables consumption and ovarian cancer were ultimately included in our meta-analysis [9,16-25].

\section{Study characteristics and quality}

A total of 4,306 cases in 375,562 controls in 11 independent studies were identified. Among the 11 studies, there were 5 cohort studies and 6 case-control studies. Overall, 7 studies was a population based study and the rest 4 studies were hospital based studies. The geographicical distribution of the studies sties was 4 were in European, 4 in Americas, 2 in Asia and 1 in Australia. The detailed age, gender distribution, duration of studies, and adjustments of confounding factors were demonstrated in Table 1.

Study quality was judged on the basis of the NewcastleOttawa Scale (1-9 stars). The scale distribution was from 5 to 8 stars. Among the 11 included studies, all studies 


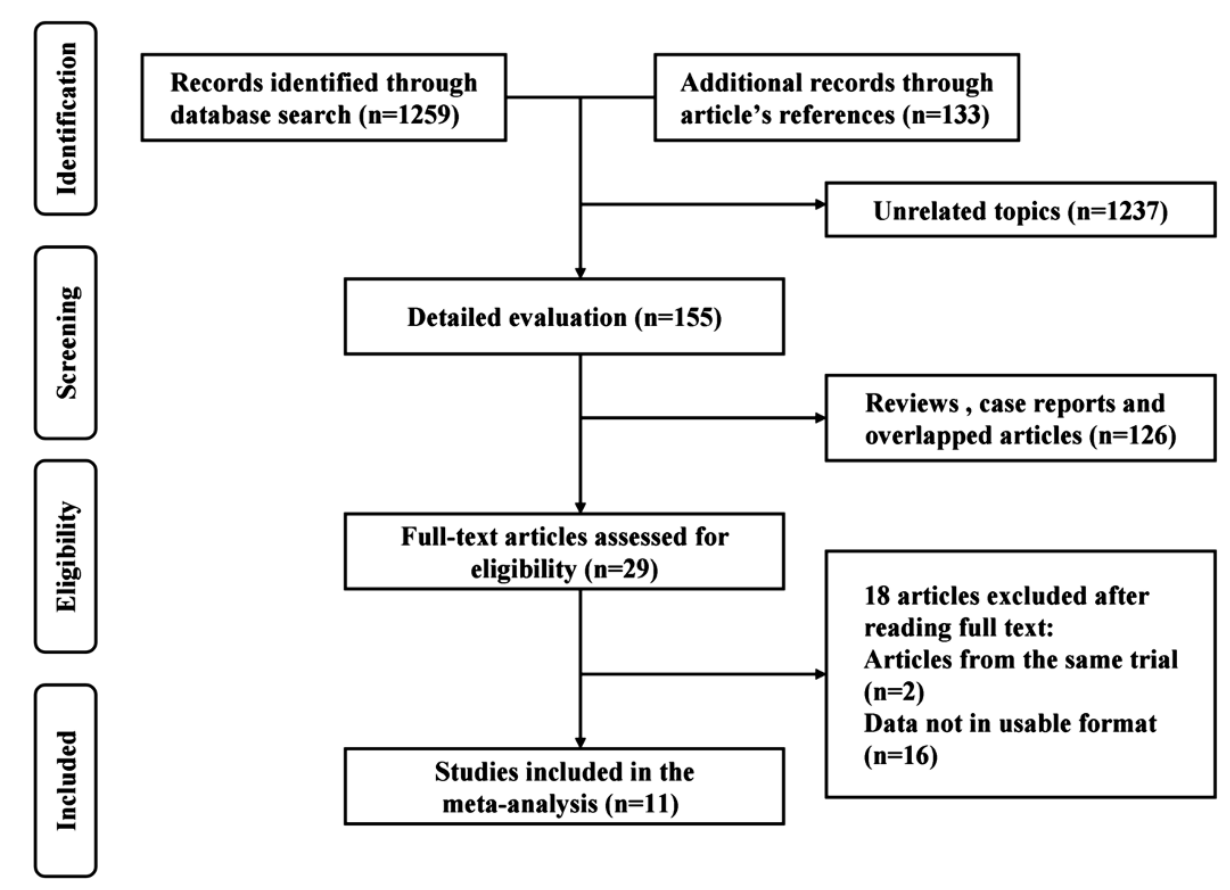

Figure 1 Flow chart of the literature search. The literature search was conducted in Medline and EMBASE. The reference lists of the relevant studies were reviewed as well.

demonstrated a relatively high quality (more than 6 stars in NOS) (Table 2).

\section{Cruciferous vegetable consumption and ovarian cancer}

The overall analysis of all 11 studies, including the casecontrol and cohort studies, found that cruciferous vegetable intake was associated with a reduced risk of ovarian cancer $(n=11, R R=0.90 ; 95 \%$ CI: 0.82- 0.98, Figure 2). The subgroup analyses were conducted by the study designs, population or hospital based design and study sites. The effect of cruciferous vegetable consumption and ovarian cancer was detected discretely in the subgroup analyses. Cruciferous vegetable consumption was associated with a reduced risk of ovarian cancer in case-control studies ( $\mathrm{n}=6, \mathrm{RR}=0.84$; 95\% CI, 0.75-0.94) but not in cohort studies $(n=5, R R=1.00 ; 95 \% C I, 0.85-1.11)$. When the data source was considered, the significant association was detected in the hospital-based studies $(\mathrm{n}=4, \mathrm{RR}, 0.82$; 95\% CI, 0.72-0.94) but not in the population-based group ( $\mathrm{n}=7$, RR, 0.95; 95\% CI, 0.85-1.07). When the geographical distribution was considered, only the studies conducted in the Europe demonstrated a significant result ( $\mathrm{n}=4$, RR, 0.88; 95\% CI, 0.79-0.99) (Table 2).

\section{Test for the heterogeneity}

The heterogeneity was statistically significant when all the studies were pooled together $\left(\mathrm{I}^{2}=25.2 \% ; \mathrm{P}=0.284\right)$. When the included studies were excluded one by one and re-count the heterogeneity and the analyses did not identify change of the significance of the heterogeneity. The advanced subgroup analyses by study designs, study sites, and case group definitions demonstrated no significant results in the heterogeneity.

\section{Sensitivity analysis and publication bias}

The sensitivity analysis was performed by excluding the included studies from the meta-analysis. The result showed that no one study could influence the significance of the conclusion. No indication of publication bias was observed in the literature on tea (Begg's funnel plot, symmetrical, Figure 3; Begg's test, $P=0.310$; Egger's test, $P=0.417$ ).

\section{Discussion}

A total of 4,306 cases in 375,562 controls in 11 independent studies were identified in this current metaanalysis. The result of this current meta-analysis, including 6 case-control and 5 cohort studies, indicated that cruciferous vegetable intake was associated with a reduced risk of ovarian cancer. When stratified by the study designs, although the meta-analysis from the case-control studies suggested a moderate reduction in risk, the results from the cohort studies were null. The heterogeneity was not significant when all the 11 studies were pooled in the meta-analysis. Publication bias was not detected in the meta-analysis. The results of the sensitivity analysis suggest that the conclusions of this study were quite robust. 
Table 1 Study characteristics of published cohort and case-control studies on egg intake and ovarian cancer

\begin{tabular}{|c|c|c|c|c|c|c|c|}
\hline $\begin{array}{l}\text { Author } \\
\text { publication year }\end{array}$ & Country & $\begin{array}{l}\text { Study } \\
\text { period }\end{array}$ & Study design & $\begin{array}{l}\text { No. of } \\
\text { subjects }\end{array}$ & Cases & $\begin{array}{l}\text { FFQ used for } \\
\text { dietary assessment }\end{array}$ & Confounders for adjustment \\
\hline La Vecchia C1987 & Italy & 1979-1986 & Hospital-based case-control study & 1,380 & 445 & Yes & $\begin{array}{l}\text { Age, interviewer, marital status, social class, education, parity, } \\
\text { age at first birth, age at menarche, menopausal status, age at } \\
\text { menopause, BMl, oral contraceptive and other female hormone } \\
\text { use, retinol and carotene indices, added score of fat consumption } \\
\text { and alcohol intake }\end{array}$ \\
\hline Engle A 1991 & USA & 1984-1989 & Hospital-based case-control study & 212 & 72 & Yes & Age and smoking status \\
\hline Fairfield KM 2001 & USA & 1976-1996 & Population-based cohort study & 80,326 & 527 & Yes & $\begin{array}{l}\text { Age, BMl, duration of oral contraception use, smoking history, } \\
\text { parity, history of tubal ligation, total energy, and dietary fiber }\end{array}$ \\
\hline Zhang M 2002 & China & 1999-2000 & Hospital-based case-control study & 906 & 254 & Yes & $\begin{array}{l}\text { Age at interview, education, living area, BMI, smoking, alcohol } \\
\text { drinking, tea drinking, family income, marital and menopause status, } \\
\text { parity, tubal ligation, oral contraceptive use, physical activity, family } \\
\text { history of ovarian cancer, total energy intake, fruit, milk, } \\
\text { fish, meat, egg intake }\end{array}$ \\
\hline Pan SY 2004 & Canada & 1994-1997 & Case-control study population-based & 2,577 & 442 & Yes & $\begin{array}{l}\text { Age, province of residence, education, alcohol consumption, } \\
\text { cigarette pack-years, BMl, total caloric intake, recreational } \\
\text { physical activity, number of live births, menstruation years, } \\
\text { and menopause status }\end{array}$ \\
\hline Larsson SC 2004 & Sweden & 1987-1990 & Population-based cohort study & 61,084 & 266 & Yes & $\begin{array}{l}\text { Age, BMI, educational level, parity, oral contraceptive use, } \\
\text { fish consumption, and dietary lactose intake, } \\
\text { consumption of total fruit }\end{array}$ \\
\hline Mommers M 2005 & Netherlands & 1986-1997 & Population-based cohort study & 62,573 & 252 & Yes & $\begin{array}{l}\text { Age, height, current cigarette smoker, duration of cigarette smoking, } \\
\text { number of cigarettes smoked daily, duration of oral contraceptive use, } \\
\text { parity, total fruit intake; total vegetable intake; all individual fruit or } \\
\text { vegetable items listed for all other individual fruit or vegetable item }\end{array}$ \\
\hline Sakauchi F 2007 & Japan & 1988-2003 & Population-based cohort study & 64,327 & 54 & Yes & $\begin{array}{l}\text { Age, menopausal status, number of pregnancies, history of } \\
\text { sex hormone use, BMI, physical activity, and education }\end{array}$ \\
\hline Chang ET 2007 & USA & 1995-2003 & Population-based cohort study & 97,275 & 280 & Yes & $\begin{array}{l}\text { Age, race, total energy intake, parity, oral contraceptive use, } \\
\text { strenuous exercise, wine consumption, and menopausal } \\
\text { status/hormone therapy use }\end{array}$ \\
\hline Kolahdooz F 2009 & Australia & 1990-1993 & Population-based case-control study & 1,460 & 683 & Yes & $\begin{array}{l}\text { Age, oral contraceptive use, parity, education after } \\
\text { high school, and energy intake }\end{array}$ \\
\hline Bosetti C 2012 & Italy and Switzerland & $1991-2009$ & Hospital-based case-control study & 3,442 & 1,031 & Yes & $\begin{array}{l}\text { Age, study center, year of interview, education, BMI, } \\
\text { alcohol drinking, tobacco smoking, and total energy intake }\end{array}$ \\
\hline
\end{tabular}


Table 2 Subgroup analysis of cruciferous vegetables consumption and the risk of ovarian cancer

\begin{tabular}{|c|c|c|c|c|c|}
\hline & \multirow[t]{2}{*}{ No. of studies } & \multicolumn{2}{|c|}{ Pooled estimate } & \multicolumn{2}{|c|}{ Tests of heterogeneity } \\
\hline & & RR & $95 \% \mathrm{Cl}$ & $P$ value & $I^{2}(\%)$ \\
\hline All studies & 11 & 0.90 & $0.82-0.98$ & 0.204 & 25.2 \\
\hline \multicolumn{6}{|l|}{ Study design } \\
\hline Cohort & 5 & 1.00 & $0.85-1.11$ & 0.897 & 0.0 \\
\hline Case-control & 6 & 0.84 & $0.75-0.94$ & 0.091 & 47.4 \\
\hline \multicolumn{6}{|l|}{ Study location } \\
\hline Europe & 4 & 0.88 & $0.79-0.99$ & 0.656 & 0.0 \\
\hline North America & 4 & 0.88 & $0.77-1.02$ & 0.043 & 63.2 \\
\hline Asia & 2 & 0.84 & $0.53-1.34$ & 0.217 & 34.5 \\
\hline Australia & 1 & 1.16 & $0.81-1.67$ & / & / \\
\hline \multicolumn{6}{|l|}{ Data source } \\
\hline Hospital-based & 4 & 0.82 & $0.72-0.94$ & 0.119 & 48.8 \\
\hline Population-based & 7 & 0.95 & $0.85-1.07$ & 0.577 & 0.0 \\
\hline
\end{tabular}

The data in bold demonstrate significant results.

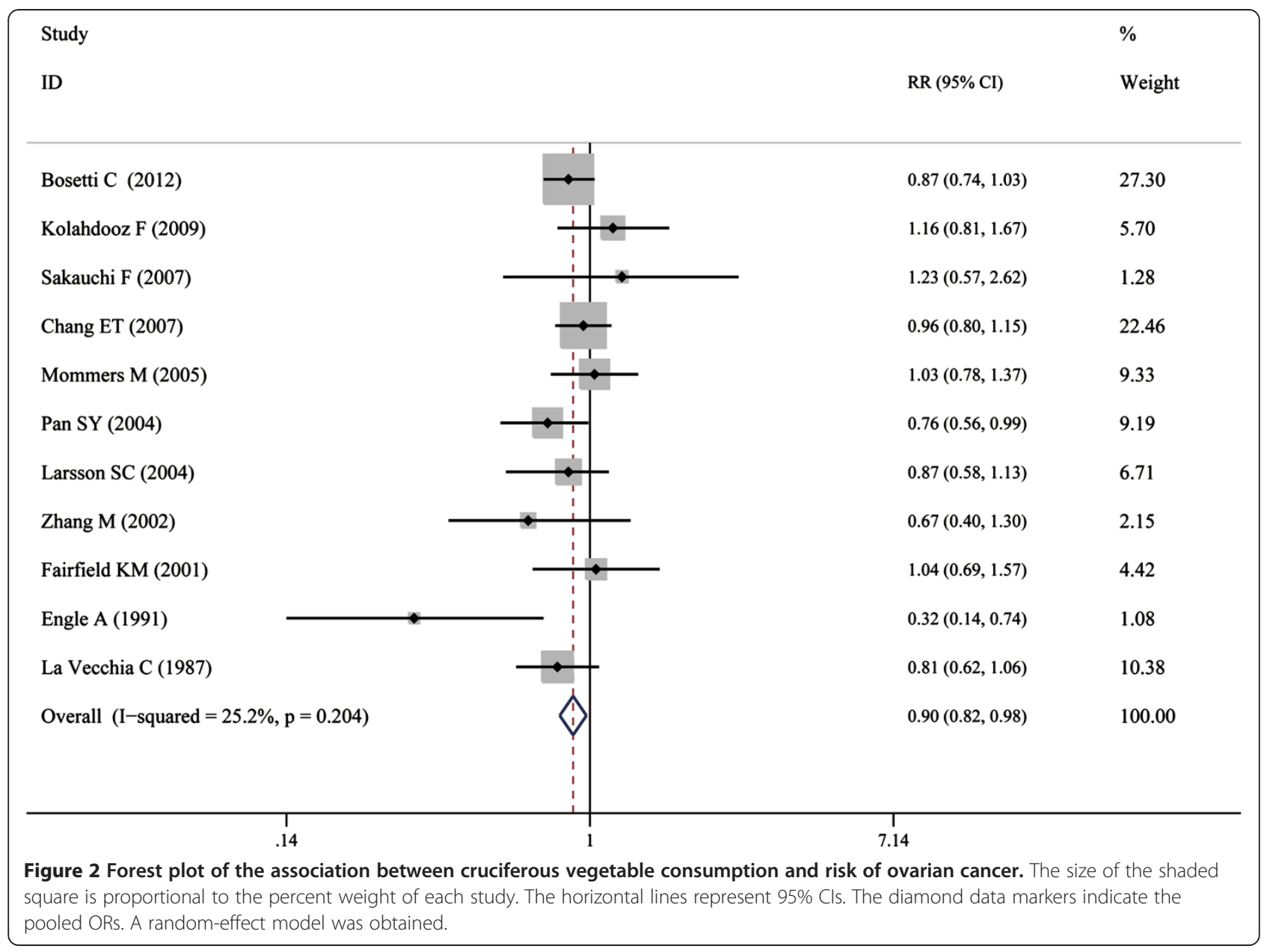




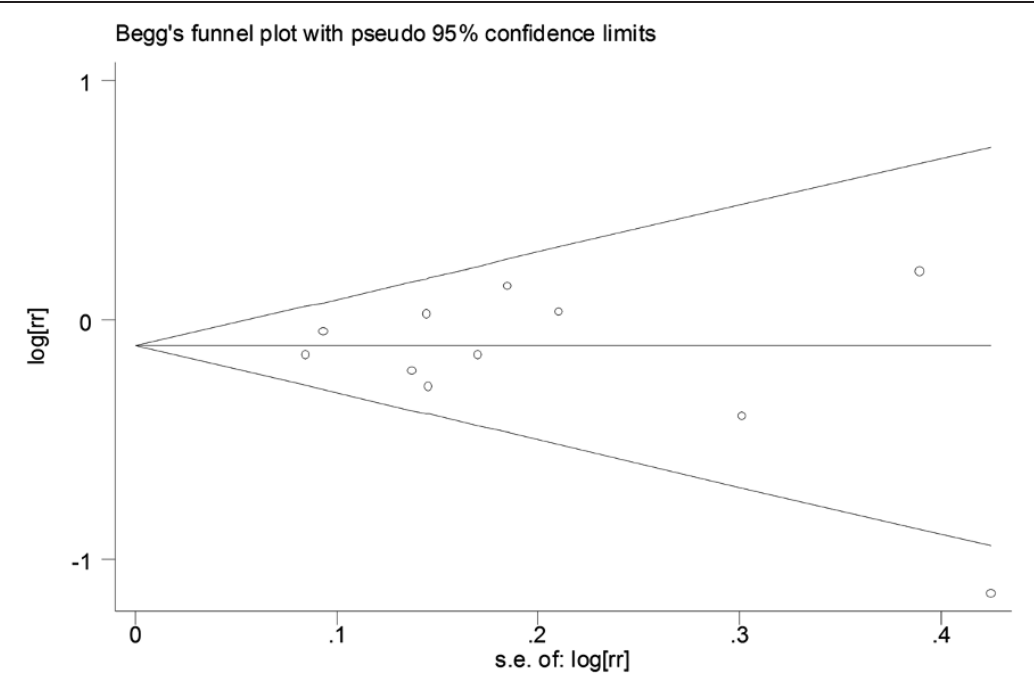

Figure 3 Funnel plot of all the included studies. Funnel plot of the RR (for the highest vs the lowest consumption categories) vs the standard error of the log RR for studies evaluating cruciferous vegetable consumption and ovarian cancer.

Several in-vitro studies have tried to explore the link between cruciferous vegetables and cancer. Cruciferous vegetables are good sources of a variety of nutrients and phytochemicals that may have excellent cancer fighting properties [26]. The cancer-protective effects of cruciferous vegetables likely involve complex interactions of multiple mechanisms, and most research to date has focused on the capacity of cruciferous vegetable ingredients to alter biotransformation enzyme expression and activities. It has been long mentioned that cruciferous vegetables was associated with a reduced risk of ovarian cancer. In 1991, Engle et al. conducted a case-control study in which a total of 71 cases and 141 matched controls were investigated [21]. The result of this case-control studies demonstrated that cruciferous vegetable intake would reduce the incidence of ovarian cancer. In a population-based study in Canada, cruciferous vegetable consumption demonstrate prospective effect on the incidence of ovarian cancer [19]. In this metaanalysis, the results showed that cruciferous vegetable consumption was a prospective factor for the ovarian cancer.

In this study, the prospective effect of cruciferous vegetable consumption on the incidence of ovarian cancer was detected in case-controls but not cohort studies. Compared with retrospective studies, prospective studies are less susceptible to bias (e.g. recall bias, selection bias) due to their nature. Furthermore, case-control studies had a lower quality score than prospective studies. He difference between results from meta-analysis of case-control and cohort studies indicated that the association may have been changed by poor study methodologies. Likewise, in the subgroup analyses by type of control subjects, the protective effect in hospital-based control subjects was stronger than that in population-based ones, which might mean hospital-based case-control studies more inclined to selection bias. For the subgroup analysis of cruciferous vegetable intake and ovarian cancer risk by geographical site, the studies conducted in the Europe that egg consumption was a risk factor of the incidence of ovarian cancer but not the studies in the America, Asia and Australia. The geographical differences, the diet diversity and ethnic and genetic disparity are the possible reasons of the significant changes of the outcomes.

The strengths of this study include as follows: [1] we adopted a relative comprehensive literature search strategy in the acquisition of the potential included studies. We search the data base with key words of "diet" in combine with ovarian cancer and thus it would help to avoid missing includable articles. [2] All of the included studies included in this meta-analysis demonstrate a relative high quality. The results of the sensitivity analysis and the publication bias detection suggest that the conclusions of this study were quite robust, which may add strength to the conclusions drawn. [3] Consummate analyses, including detailed subgroup analyses, were conducted in this metaanalysis. The consummate analyses would provide us more detailed knowledge of the relation between egg consumption and risk of ovarian cancer.

As with any meta-analysis of observational studies, our study has several limitations. Firstly, half of the studies followed a case-control study design, and therefore there were recall and selection bias which are inherent to retrospective studies. Even through the subgroup analyses by the study designs were conducted, the efficiency was limited by the absence of enough cohort studies. Secondly, the data of included studies were not enough for us to conduct a dose-response meta-analysis. There points all indicate the requirement of additional well-designed studies in the future. 


\section{Conclusions}

In summary, this meta-analysis suggested that high intake of cruciferous vegetable can decrease risk of ovarian cancer. More in-depth studies are warranted to report more detailed results, including other specific vegetables within the cruciferous vegetable family, stratified results by ovarian cancer site, subtype of ovarian cancer, food preparation methods, or adjustment for potential confounders.

\section{Competing interests}

The authors declare that they have no competing interests.

\section{Authors' contributions}

$\mathrm{BH}$ and TY conceived the study idea and designed the study. $\mathrm{BH}$ and XPL reviewed the literature and performed statistical analyses. BH, XPL and TY extracted data and drafted the manuscript. $\mathrm{BH}$ reviewed and edited the manuscript. All authors read and approved the final manuscript.

Received: 9 December 2013 Accepted: 21 December 2013 Published: 20 January 2014

\section{Reference}

1. Jemal A, Siegel R, Ward E, Murray T, Xu J, Thun MJ: Cancer statistics, 2007. CA Cancer J Clin 2007, 57:43-66.

2. Gun BD, Bahadir B, Bektas S, Barut F, Yurdakan G, Kandemir NO, Ozdamar SO: Clinicopathological significance of fascin and CD44v6 expression in endometrioid carcinoma. Diagn Pathol 2012, 7:80.

3. Ozer $\mathrm{H}$, Yenicesu $\mathrm{G}$, Arici $\mathrm{S}$, Cetin $\mathrm{M}$, Tuncer $\mathrm{E}$, Cetin A: Immunohistochemistry with apoptotic-antiapoptotic proteins (p53, p21, bax, bcl-2), c-kit, telomerase, and metallothionein as a diagnostic aid in benign, borderline, and malignant serous and mucinous ovarian tumors. Diagn Pathol 2012, 7:124

4. Wang L, Jin X, Lin D, Liu Z, Zhang X, Lu Y, Liu Y, et al: Clinicopathologic significance of claudin-6, occludin, and matrix metalloproteinases -2 expression in ovarian carcinoma. Diagn Pathol 2013, 8:190

5. Parkin DM, Bray F, Ferlay J, Pisani P: Global cancer statistics, 2002. CA Cancer J Clin 2005, 55:74-108.

6. Genkinger JM, Hunter DJ, Spiegelman D, Anderson KE, Beeson WL, Buring JE, Colditz GA, et al: A pooled analysis of 12 cohort studies of dietary fat, cholesterol and egg intake and ovarian cancer. Cancer Causes Control 2006, 17:273-285

7. Riman T, Nilsson S, Persson IR: Review of epidemiological evidence for reproductive and hormonal factors in relation to the risk of epithelial ovarian malignancies. Acta Obstet Gynecol Scand 2004, 83:783-795.

8. Verkerk R, Schreiner M, Krumbein A, Ciska E, Holst B, Rowland I, De Schrijver R, et al: Glucosinolates in Brassica vegetables: the influence of the food supply chain on intake, bioavailability and human health. Mol Nutr Food Res 2009, 53(2):S219.

9. Bosetti C, Filomeno M, Riso P, Polesel J, Levi F, Talamini R, Montella M, et al: Cruciferous vegetables and cancer risk in a network of case-control studies. Ann Oncol 2012, 23:2198-2203.

10. de Matos LL, Del Giglio AB, Matsubayashi CO, de Lima FM, Del Giglio A, da Silva Pinhal MA: Expression of CK-19, galectin-3 and HBME-1 in the differentiation of thyroid lesions: systematic review and diagnostic meta-analysis. Diagn Pathol 2012, 7:97.

11. Stroup DF, Berlin JA, Morton SC, Olkin I, Williamson GD, Rennie D, Moher D, et al: Meta-analysis of observational studies in epidemiology: a proposal for reporting. Meta-analysis of observational studies in epidemiology (MOOSE) group. JAMA 2000, 283:2008-2012.

12. Moher D, Liberati A, Tetzlaff J, Altman DG: Preferred reporting items for systematic reviews and meta-analyses: the PRISMA statement. BMJ 2009, 339:b2535.

13. Stang A: Critical evaluation of the Newcastle-Ottawa scale for the assessment of the quality of nonrandomized studies in meta-analyses. Eur J Epidemiol 2010, 25:603-605

14. Begg CB, Mazumdar M: Operating characteristics of a rank correlation test for publication bias. Biometrics 1994, 50:1088-1101.

15. Egger M, Davey Smith G, Schneider M, Minder C: Bias in meta-analysis detected by a simple, graphical test. BMJ 1997, 315:629-634.
16. Sakauchi F, Khan MM, Mori M, Kubo T, Fujino Y, Suzuki S, Tokudome S, et al: Dietary habits and risk of ovarian cancer death in a large-scale cohort study (JACC study) in Japan. Nutr Cancer 2007, 57:138-145.

17. Kolahdooz F, Ibiebele TI, van der Pols JC, Webb PM: Dietary patterns and ovarian cancer risk. Am J Clin Nutr 2009, 89:297-304.

18. Larsson SC, Holmberg L, Wolk A: Fruit and vegetable consumption in relation to ovarian cancer incidence: the Swedish mammography cohort. Br J Cancer 2004, 90:2167-2170.

19. Pan SY, Ugnat AM, Mao Y, Wen SW, Johnson KC: A case-control study of diet and the risk of ovarian cancer. Cancer Epidemiol Biomarkers Prev 2004, 13:1521-1527.

20. La Vecchia C, Decarli A, Negri E, Parazzini F, Gentile A, Cecchetti G, Fasoli M, et al: Dietary factors and the risk of epithelial ovarian cancer. J Natl Cancer Inst 1987, 79:663-669.

21. Engle A, Muscat JE, Harris RE: Nutritional risk factors and ovarian cancer. Nutr Cancer 1991, 15:239-247.

22. Fairfield KM, Hankinson SE, Rosner BA, Hunter DJ, Colditz GA, Willett WC: Risk of ovarian carcinoma and consumption of vitamins $A, C$, and $E$ and specific carotenoids: a prospective analysis. Cancer 2001, 92:2318-2326.

23. Zhang $M$, Yang $Z Y$, Binns $C W$, Lee $A H$ : Diet and ovarian cancer risk: a case-control study in China. Br J Cancer 2002, 86:712-717.

24. Mommers M, Schouten $L$, Goldbohm RA, van den Brandt PA: Consumption of vegetables and fruits and risk of ovarian carcinoma. Cancer 2005, 104:1512-1519.

25. Chang ET, Lee VS, Canchola AJ, Clarke CA, Purdie DM, Reynolds P, Anton-Culver $\mathrm{H}$, et al: Diet and risk of ovarian cancer in the California teachers study cohort. Am J Epidemiol 2007, 165:802-813.

26. Bryant CS, Kumar S, Chamala S, Shah J, Pal J, Haider M, Seward S, et al: Sulforaphane induces cell cycle arrest by protecting RB-E2F-1 complex in epithelial ovarian cancer cells. Mol Cancer 2010, 9:47.

doi:10.1186/1746-1596-9-7

Cite this article as: Han et al:: Cruciferous vegetables consumption and the risk of ovarian cancer: a meta-analysis of observational studies. Diagnostic Pathology 2014 9:7.

\section{Submit your next manuscript to BioMed Central and take full advantage of:}

- Convenient online submission

- Thorough peer review

- No space constraints or color figure charges

- Immediate publication on acceptance

- Inclusion in PubMed, CAS, Scopus and Google Scholar

- Research which is freely available for redistribution 